\title{
PERBEDAAN PENGETAHUAN TENTANG MAKANAN PENDAMPING ASI PADA IBU DENGAN BALITA GIZI KURANG USIA 6-24 BULAN SEBELUM DAN SESUDAH MENDAPATKAN PENYULUHAN DI DESA MUDUNG KECAMATAN KEPOHBARU BOJONEGORO
}

\author{
Prasita Ayu Widyaningtyas \\ Departemen Promosi Kesehatan dan Ilmu Perilaku Fakultas Kesehatan Masyarakat \\ Universitas Airlangga \\ Email : prasita.ayu.widyaningtyas-2015@fkm.unair.ac.id
}

\begin{abstract}
Baby growth can be hampered if only given breast milk without getting breast milk supplementary food (MPASI) after the age of 6 months, because nutrients are not fulfilled for growth and development. However, if MPASI is given early it can cause negative problems in infants such as allergies and digestive disorders. One of the causes of malnutrition is due to the lack of knowledge of mothers about giving complementary feeding to infants. So that the mother provides complementary feeding at an earlier age and the type of food that is not suitable for the baby's age. This study aims to determine the differences in knowledge about complementary foods in mothers with underweight children aged 6-24 months before and after getting counseling in Mudung Village, Kepohbaru Bojonegoro Subdistrict. This study uses the preexperimental method with the type of research using the one group pre test post test design. The sample in this study used a total sampling of 13 people. The data collection method used is a knowledge questionnaire. Data analysis was done by paired t test. Based on the results of the statistical test with paired t test obtained p value of (0.047) where the value of $p$ value <0.05. Based on the results of the study it can be concluded that there is a significant difference between mother's knowledge about MP ASI to children aged 6-24 months before and after getting counseling. It is expected that mothers can apply complementary feeding behavior to infants aged 6-24 months correctly and accordingly in order to improve the nutritional status of infants and follow-up health workers to further improve health counseling to further improve health counseling about complementary foods.
\end{abstract}

\section{Keyword: counseling,complementary feeding, knowledge}

Abstrak: Pertumbuhan bayi dapat terhambat apabila hanya diberi Air Susu Ibu (ASI) saja tanpa mendapat Makanan Pendamping Air Susu Ibu (MPASI) setelah berusia 6 bulan, karena tidak terpenuhinya zat gizi untuk pertumbuhan dan perkembangan. Namun, apabila MPASI diberikan secara dini dapat menimbulkan masalah negatif pada bayi seperti alergi dan gangguan pencernaan. Salah satu penyebab masalah gizi kurang karena tingkat pengetahuan ibu yang kurang tentang pemberian MPASI pada bayi. Sehingga ibu memberikan MPASI pada usia lebih dini dan jenis makanan MPASI yang tidak sesuai dengan usia bayi. Penelitian ini bertujuan untuk mengetahui perbedaan pengetahuan tentang makanan pendamping asi pada ibu dengan balita gizi kurang usia 6-24 bulan sebelum dan sesudah mendapatkan penyuluhan di Desa Mudung Kecamatan Kepohbaru Bojonegoro. Penelitian ini menggunakan metode pre-eksperimental dengan jenis penelitian menggunakan rancangan one grup pre test post test. Sampel dalam penelitian ini menggunakan total sampling sebanyak 13 orang. Metode pengumpulan data yang digunakan adalah kuesioner pengetahuan. Analisis data dilakukan dengan paired $t$ test. Berdasarkan hasil dari uji statistik dengan paires $t$ test diperoleh $p$ value sebesar (0.047) dimana nilai $p$ value $<0,05$. Berdasarkan hasil penelitian dapat disimpulkan bahwa terdapat perbedaan yang signifikan antara pengetahuan ibu tentang MP ASI kepada balita usia 6-24 bulan sebelum dan sesudah mendapatkan penyuluhan. Diharapkan ibu dapat menerapkan perilaku pemberian makanan pendamping ASI pada bayi umur 6-24 bulan secara benar dan sesuai agar meningkatkan status gizi bayi serta tindak lanjut petugas kesehatan untuk lebih meningkatkan penyuluhan kesehatan untuk lebih meningkatkan penyuluhan kesehatan tentang makanan pendamping ASI.

Kata Kunci : Penyuluhan, MP ASI, Pengetahuan 
Indonesia merupakan negara yang tidak lepas dengan masalah kesehatan yaitu gizi. Gizi kurang menjadi salah satu fokus kesehatan oleh pemerintah Indonesia. Salah satu masalah gizi adalah gizi kurang atau susunan nutrisi makanan yang tidak seimbang atau makanan yang tidak memenuhi kebutuhan gizi tubuh seseorang. Gizi kurang bisa terjadi pada seluruh kalangan umur. Namun, anak dengan usia 1-5 tahun merupakan usia yang rentan sangat terkena kekurangan gizi (KEP) (Sediaoetama, 2000). Menurut Kementerian Kesehatan Republik Indonesia, usia 0-2 tahun juga merupakan umur yang rentan terkena gizi kurang karena pada usia tersebut masa tumbuh kembang masih sangat optimal (golden period) sehingga apabila sudah mengalami masalah ditakutkan akan berdampak negatif (Kemenkes RI, 2016).

Anak yang menderita gizi kurang sejak dini akan mengakibatkan pertumbuhan jasmani terganggu hingga dewasa. Gizi kurang merupakan salah satu faktor yang menyebabkan kecerdasan anak terganggu. Apabila dalam masyarakat terlalu banyak yang menderita gizi kurang maka masyarakat tersebut akan sulit untuk berkembang. Gizi kurang jelas menjadi masalah bersama sehingga diperlukan suatu tindakan untuk perbaikan gizi yang lebih baik (Adriani, 2012)

Berdasarkan Data Pemantauan Gizi Menurut Provinsi 2016, jumlah kejadian gizi kurang tertinggi terjadi di provinsi Nusa Tenggara Timur sejumlah $21,3 \%$, urutan kedua adalah Kalimantan Barat sejumlah 20,8\%. Sedangkan, Provinsi Jawa Timur berada pada posisi ke-16 kejadian gizi kurang. Berdasarkan hasil pengukuran status gizi PSG 2016 dengan indeks $\mathrm{BB} / \mathrm{U}$ pada balita 0-23 bulan persentase gizi kurang terjadi sebesar $11,8 \%$ yaitu hampir sama jika dibandingkan dengan hasil PSG 2015 gizi kurang sebesar 11,9\% (Kemenkes, 2016). Berdasarkan hasil PSG (Pemantauan Status Gizi) tahun 2017, Kabupaten Bojonegoro termasuk dalam kategori akut dengan angka gizi kurang sebesar $16,4 \%$, stunting sebesar 19,2\%, dan wasting sebesar 7,2\%. Proporsi gizi kurang pada balita di Kabupaten Bojonegoro tahun 2016 sebesar 5,71\% (Profil Kesehatan Kabupaten Bojonegoro, 2016).

Berdasarkan profil Ponkesdes Mudung tahun 2016, Desa Mudung merupakan salah satu desa di Kecamatan Kepohbaru yang memiliki 3 dusun (Dusun Tlanak, Dusun Budug, dan Dusun Mudung). Jumlah penduduk Desa Mudung yaitu sebesar 1.901 jiwa yang terdiri dari laki-laki 980 jiwa dan perempuan 921 jiwa. Persebaran penduduk berdasarkan usia paling banyak pada usia 15-44 tahun dan yang paling sedikit pada usia $\leq 1$ tahun. Desa Mudung Kecamatan Kepohbaru merupakan salah satu wilayah yang ditemukan kejadian gizi kurang. Berdasarkan data Ponkesdes Desa Mudung tahun 2017, kejadian gizi kurang pada balita sebesar 16\%. Selain itu, berdasarkan data KIA Desa Mudung tahun 2017, kasus ibu hamil dengan risiko tinggi sebesar 35\%. Berdasarkan hasil studi pendahuluan yang dilakukan pada Januari 2018 kepada Bidan Desa Mudung, beliau mengatakan bahwa perlu diadakan intervensi terkait dengan gizi kurang pada balita (Data Ponkesdes Desa Mudung, 2017)

Makanan Pendamping ASI (MP ASI) merupakan makanan yang mengandung zat gizi yang dapat diberikan kepada bayi setelah usia 6 bulan. Pada usia 0-6 bulan, bayi harus mendapatkan asi eksklusif agar nutrisi dalam tubuh terpenuhi. MP ASI dapat berupa pemberian bubur, tim, biskuit, dan sari buah. Pemberian Makanan Pendamping ASI dapat dilihat dari usia bayi agar frekuensi yang diberikan juga sesuai (Gibson, 2008).

Salah satu upaya yang dapat digunakan untuk meningkatkan pengetahuan adalah dengan dilakukan upaya promosi kesehatan. Promosi kesehatan dapat dilakukan dengan menggunakan berbagai metode dan media yang disesuaikan dengan sasaran. Cara efektif dalam pendekatan kelompok adalah dengan penyuluhan. Dengan penyuluhan dapat membuat perubahan perilaku seseorang ke arah yang lebih baik dengan saling tukar pengalaman sesama sasaran (Notoatmodjo, 2007).

Berdasarkan latar belakang permasalahan di atas, maka rumusan masalah dalam penelitian ini adalah bagaimana perbedaan pengetahuan tentang makanan pendamping asi pada ibu dengan balita gizi kurang usia 6-24 bulan sebelum dan sesudah mendapatkan penyuluhan di Desa Mudung Kecamatan Kepohbaru Bojonegoro. Penelitian ini bertujuan 
untuk mengetahui perbedaan pengetahuan tentang makanan pendamping asi pada ibu dengan balita gizi kurang usia 6-24 bulan sebelum dan sesudah mendapatkan penyuluhan di Desa Mudung Kecamatan Kepohbaru Bojonegoro. Hasil penelitian ini diharapkan dapat menjadi masukan bagi pihak puskesmas bahwa untuk menyampaikan informasi terkait dengan makanan pendamping ASI dapat dilakukan dengan metode penyuluhan.

\section{METODE}

Penelitian ini menggunakan Pre Experimental Design dengan bentuk desain one grup pre- test dan post- test.Dalam penelitian ini tidak menggunakan kelompok kontrol. Namun, sebelum dilakukan perlakuan diberikan pre- test, setelah perlakuan diberikan posttest. Berikut adalah desain penelitian dengan one grup pre test dan post test.

\begin{tabular}{lcl}
\hline Pre Test & Perlakuan & Post Test \\
\hline $\mathrm{O}_{1}$ & $\mathrm{X}$ & $\mathrm{O}_{2}$ \\
\hline
\end{tabular}

Sumber: Sugiyono, 2016

Keterangan:

$\mathrm{O} 1=$ Nilai pretest sebelum diberi perlakuan (treatment).

$\mathrm{O} 2=$ Nilai posttest setelah mendapat perlakuan (treatment).

$\mathrm{X}=$ Perlakuan dengan menerapkan penyuluhan terkait dengan makanan pendamping ASI.

Sampel merupakan sejumlah karakteristik yang dimiliki oleh populasi yang digunakan untuk penelitian (Sujarweni, 2012). Sampel dalam penelitian ini sebanyak 13 orang atau total sampling. Penemuan sampel berdasarkan jumlah ibu yang memiliki anak usia 6-24 bulan dengan gizi kurang di desa mudung kecamatan kepohbaru bojonegoro. Pengumpulan data menggunakan kuisioner pengetahuan terkait dengan makanan pendamping ASI sebanyak 15 pertanyaan. Analisis data yang digunakan adalah paired $t$ test.

HASIL PENELITIAN

Tabel 1. Karakteristik Subyek Penelitian Berdasarkan Umur

\begin{tabular}{ccc}
\hline Umur & Frekuensi & \% \\
\hline $20-25$ & 3 & 23.1 \\
$26-30$ & 8 & 61.5 \\
$31-35$ & 2 & 15.4 \\
\hline Total & 13 & 100 \\
\hline
\end{tabular}

Berdasarkan Tabel 1, umur responden terbanyak berada pada usia 26- 30 tahun sebanyak $61.5 \%$. Sedangkan umur responden paling sedikit berada pada usia antara 31-35 tahun. Hal ini disebabkan karena pada masa tersebut tingkat kesuburan seorang wanita mengalami penurunan. Sehingga, untuk mengalami kehamilan akan menimbulkan kecemasan.

Tabel 2. Karakteristik Subyek Penelitian Berdasarkan Pendidikan

\begin{tabular}{ccc}
\hline Pendidikan & Frekuensi & \% \\
\hline SD & 2 & 15.4 \\
SMP & 5 & 38.5 \\
SMA & 4 & 30.8 \\
PT & 2 & 15.4 \\
\hline Total & 13 & 100 \\
\hline
\end{tabular}

Berdasarkan Tabel 2, pendidikan responden dibagi menjadi empat kategori yaitu SD, SMP, SMA, dan perguruan tinggi. Frekuensi pendidikan terbanyak terjadi pada pendidikan SMP sebanyak $38.5 \%$. Sedangkan frekuensi pendidikan sedikit terjadi pada pendidikan SD dan perguruan tinggi sebanyak $15.4 \%$. Pendidikan yang tinggi dapat membuat pengetahuan juga semakin tinggi. Pengetahuan merupakan hasil dari tahu setelah seseorang melakukan penginderaan terhadap suatu objek. Semakin tinggi pendidikan, semakin banyak informasi yang diperoleh sehingga dapat menyebabkan pengetahuan yang diperoleh juga tinggi. 
Pengetahuan yang tinggi juga dapat berdampak pada sikap yang positif terkait dengan makanan pendamping ASI.

Tabel 3. Distribusi Tingkat Pengetahuan Sebelum Mendapatkan Penyuluhan

\begin{tabular}{ccc}
\hline Tingkat Pengetahuan & Frekuensi & \% \\
\hline Kurang & 0 & 0 \\
Cukup & 6 & 46.2 \\
Baik & 7 & 53.8 \\
\hline Total & 13 & 100 \\
\hline
\end{tabular}

Berdasarkan Tabel 3, distribusi tingkat pengetahuan pada ibu balita dengan gizi kurang usia 6-24 bulan adalah kategori kurang sebanyak $0 \%$, kategori cukup sebanyak 6 orang $(46,2 \%)$, kategori baik sebanyak 7 orang $(53.8 \%)$.

Tabel 4. Distribusi Tingkat Pengetahuan Sesudah Mendapatkan Penyuluhan

\begin{tabular}{ccc}
\hline Tingkat Pengetahuan & Frekuensi & \% \\
\hline Kurang & 0 & 0 \\
Cukup & 3 & 23.1 \\
Baik & 10 & 76.9 \\
\hline Total & 13 & 100 \\
\hline
\end{tabular}

Berdasarkan Tabel 4, distribusi tingkat pengetahuan pada ibu balita dengan gizi kurang usia 6-24 bulan adalah kategori kurang sebanyak 0\%, kategori cukup sebanyak 3 orang $(23.1 \%)$, kategori baik sebanyak 10 orang $(76.9 \%)$.

Tabel 5. Hasil Uji Paired T-test

\begin{tabular}{lcl}
\hline Variabel Pengetahuan & Sig. & Keterangan \\
\hline $\begin{array}{l}\text { Pre Post } \\
\text { Pos Test }\end{array}$ & 0.047 & Ho:ditolak \\
\hline Berdasarkan Tabel & 5, menunjukkan hasil dari uji & paired \\
t-test dengan hasil sig.
\end{tabular}
$(0.047)<0.05$ yang artinya Ho ditolak. Dapat disimpulkan bahwa terdapat perbedaan yang signifikan antara pengetahuan sebelum diberi penyuluhan dengan diberi penyuluhan terkait dengan makanan pendamping ASI.

\section{PEMBAHASAN}

Berdasarkan hasil penelitian yang dilakukan kepada 13 ibu yang mempunyai balita gizi kurang usia 6-24 bulan di Desa Mudung, Kecamatan Kepohbaru Bojonegoro dapat diketahui bahwa penyuluhan dapat membuat perbedaan yang signifikan terkait dengan makanan pendamping ASI. Hal ini membuktikan bahwa penyuluhan merupakan cara yang efektif untuk meningkatkan pengetahuan pada ibu balita. Pengetahuan pada ibu balita hanya terdiri dari dua macam kategori yaitu kategori cukup dan kategori baik. Tidak terdapat kategori rendah karena berdasarkan observasi ibu balita di Desa Mudung pernah mendapatkan penyuluhan terkait Makanan Pendamping ASI pada saat posyandu balita yang dilaksanakan setiap 1 bulan sekali.

Berdasarkan Tabel. 4 dan Tabel. 5 diperoleh hasil bahwa terjadi perbedaan sebelum dan sesudah mendapatkan penyuluhan dari kategori cukup sebelum intervensi sebanyak 46.2\% menjadi $23.1 \%$ sesudah diberi intervensi. Pada kategori baik dari $53.8 \%$ sebelum diberi intervensi menjadi $76.9 \%$ setelah diberi intervensi. Sehingga, penyuluhan mampu meningkatkan pengetahuan sebesar $23.1 \%$. Dapat dikatakan penyuluhan yang dilakukan berhasil dilaksanakan dengan baik. Penelitian ini menggunakan penyuluhan untuk meningkatkan pengetahuan terkait dengan Makanan Pendamping ASI. Penyuluhan merupakan suatu upaya yang dapat dilakukan sebagai salah satu pendekatan edukatif yang berfungsi untuk membuat perilaku individu atau masyarakat dapat meningkatkan derajat kesehatan masyarakat serta tetap mempertahankan denggan baik. Tujuan dari penyuluhan gizi adalah agar terbentuk sikap positif terhadap gizi, dan terbentuk pengetahuan dan kecakapan dalam memilih dan menggunakan bahan makanan, tercipta kebiasaan makan yang baik dan 
memunculkan motivasi untuk memahami tentang gizi seperti dengan pemberian Makanan Pendamping ASI. (Suhardjo, 2003).

Peningkatan pengetahuan juga dapat diketahui melalui Teori SOR. Menurut Skinner (1938) dalam Notoatmodjo (2010), seorang ahli psikologi merumuskan bahwa perilaku adalah respon seseorang yang terjadi akibat stimulus (rangsangan dari luar). Perubahan perilaku tergantung dari stimulus yang diberikan karena dapat menentukan keberhasilan dalam perubahan perilaku. Oleh sebab itu, dapat dikatakan bahwa perilaku seseorang dapat terjadi melalui proses stimulus - organisme - respon. Perubahan perilaku sama dengan proses belajar. Stimulus yang diberikan berupa penyuluhan terkait dengan makanan pendamping ASI yang kemudian dapat memberikan respon tertutup yaitu pengetahuan. Pengetahuan dapat diperoleh melalui proses perhatian, pengertian, dan penerimaan. Stimulus atau rangsangan dari luar dapat ditolak maupun diterima. Apabila stimulus yang diberikan diterima oleh organisme, maka stimulus tersebut dapat dikatakan efektif.

Keadaan ini serupa dengan penelitian yang dilakukan oleh Marfuah (2017) bahwa dengan dilakukan edukasi gizi terjadi peningkatan pengetahuan tentang pemberian Makanan Pendamping ASI, dari sebelum diberikan edukasi gizi sebesar 12,9 \% dan setelah diberikan edukasi gizi menjadi 29\%. Hal ini serupa dengan penelitian yang dilakukan oleh Silalahi (2012) yang memperoleh hasil bahwa sebelum memberikan penyuluhan tentang ASI Eksklusif, nilai rata- rata pengetahuan ibu sebesar 12,92 dan setelah diberikan penyuluhan, nilai rata-rata pengetahuan ibu tentang ASI eksklusif menjadi 16,07. Penyuluhan yang diberikan diharapkan mampu membuat responden yang menjadi sasaran dapat menyerap informasi lebih banyak dan kemudian dapat mengimplementasikan dalam pemberian Makanan Pendamping ASI sesuai dengan umur balita.

\section{KESIMPULAN}

Kesimpulan dalam penelitian ini adalah sebagai berikut:

a. Umur responden paling banyak terjadi pada rentang 26-30 tahun yaitu sebanyak 8 orang dengan persentase sebesar $61.5 \%$

b. Mayoritas pendidikan responden paling banyak pada jenjang pendidikan SMP yaitu sebanyak 5 orang dengan persentase sebesar $38.5 \%$

c. Responden memiliki pengetahuan cukup sebesar $46.2 \%$ sebelum diberi penyuluhan dan pengetahuan baik sebesar $53.8 \%$

d. Responden memiliki pengetahuan cukup sebesar $23.1 \%$ sesudah diberi penyuluhan dan pengetahuan baik sebesar $76.9 \%$

\section{DAFTAR PUSTAKA}

Adriani, Merryana dan Wirjatmadi, Bambang. 2012. Pengantar Gizi Masyarakat. Cetakan ke-1. Jakarta: Kencana Prenada Media Group.

Dinas Kesehatan. 2016. Profil Kesehatan Kabupaten Bojonegoro Tahun 2016. Bojonegoro

Gibson, RS,. Ferguson, EL., \& J. (2008). Complementary Foods For Infant Feeding In Developing Countries: Their Nutrient Adequacy And Improvement. European Journal of Clinical Nutrition; 421-429.

Kemenkes RI. (2016). Profil Kesehatan Indonesia Tahun 2015. Jakarta: Kementerian Kesehatan Republik Indonesia.

Marfuah, Dewy. (2017). Upaya Peningkatan Pengetahuan Ibu tentang MP Asi dengan Edukasi Gizi Melalui Booklet. Available:journal.ummgl.ac.id/index.php/urecol/article/view/1195 Diakses pada tanggal 24 Desember 2018 pukul 13.00 WIB

Notoatmodjo, S. (2007). Kesehatan Masyarakat Ilmu dan Seni. Jakarta: Rineka Cipta. Notoatmodjo, S. (2010). Promosi Kesehatan Teori dan Aplikasi. Jakarta: Rineka Cipta.

Sediaoetama, Achmad Djaeni. (2000). Ilmu Gizi untuk mahasiswa dan profesi jilid I. Jakarta: Dian Rakyat. 
Silalahi, S. L. (2012). Perbedaan Tingkat Pengetahuan Ibu Nifas Sebelum dan Sesudah Diberikan Penyuluhan Tentang ASI Eksklusif di RSUD Panembahan Senopati Bantul. Skripsi. Sekolah Tinggi Ilmu Kesehatan A. Yani Yogyakarta

Sugiyono. (2016). Metode Penelitian Kuantitatif, Kualitatif, dan $R \&$ D. Bandung: Alfabeta. Suhardjo. 2003. Berbagai Cara Pendidikan Gizi. Bumi Aksara. Jakarta.

Sujarweni, Wiratna. (2012). Statistika Untuk Penelitian. Yogyakarta: Graha ilmu 